\title{
Communication
}

\section{Spin Transition Sensors Based on $\beta$-Amino-Acid 1,2,4-Triazole Derivative}

\author{
Marinela M. Dîrtu ${ }^{1}$, France Schmit ${ }^{1}$, Anil D. Naik ${ }^{1}$, Aurelian Rotaru ${ }^{2}$, J. Marchand-Brynaert ${ }^{1}$ \\ and Yann Garcia ${ }^{1, *}$
}

1 Institute of Condensed Matter and Nanosciences, Université Catholique de Louvain, Place L.

Pasteur 1, 1348 Louvain-la-Neuve, Belgium; E-Mails: marinela.dirtu@uclouvain.be (M.M.D.); france.schmit@gmail.com (F.S.); anil.naik@uclouvain.be (A.D.N.);

jacqueline.marchand@uclouvain.be (J.M.-B.)

2 Department of Electrical Engineering and Computer Science, "Stefan cel Mare" University, University Street 13, Suceava 720229, Romania; E-Mail: aurelian.rotaru@gmail.com

* Author to whom correspondence should be addressed; E-Mail: yann.garcia@uclouvain.be; Tel.: +32-0-10472831; Fax: +32-0-10472330.

Received: 11 July 2011; in revised form: 11 August 2011 / Accepted: 12 August 2011 /

Published: 18 August 2011

Abstract: A $\beta$-aminoacid ester was successfully derivatized to yield to 4H-1,2-4-triazol-4yl-propionate ( $\beta$ Alatrz) which served as a neutral bidentate ligand in the $1 \mathrm{D}$ coordination polymer $\left[\mathrm{Fe}(\boldsymbol{\beta} \text { Alatrz })_{3}\right]\left(\mathrm{CF}_{3} \mathrm{SO}_{3}\right)_{2} \cdot 0.5 \mathrm{H}_{2} \mathrm{O}\left(\mathbf{1 \cdot 0 . 5 \mathbf { H } _ { 2 }} \mathbf{O}\right)$. The temperature dependence of the high-spin molar fraction derived from ${ }^{57} \mathrm{Fe}$ Mossbauer spectroscopy recorded on cooling below room temperature reveals an exceptionally abrupt single step transition between high-spin and low-spin states with a hysteresis loop of width $4 \mathrm{~K}\left(T_{\mathrm{c}}^{\uparrow}=232 \mathrm{~K}\right.$ and $\left.T_{\mathrm{c}}^{\downarrow}=228 \mathrm{~K}\right)$ in agreement with magnetic susceptibility measurements. The material presents striking reversible thermochromism from white, at room temperature, to pink on quench cooling to liquid nitrogen, and acts as an alert towards temperature variations. The phase transition is of first order, as determined by differential scanning calorimetry, with transition temperatures matching the ones determined by SQUID and Mössbauer

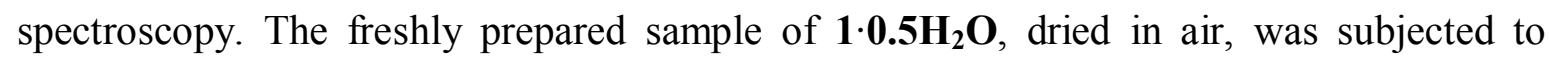
annealing at $390 \mathrm{~K}$, and the obtained white compound $\left[\mathrm{Fe}(\boldsymbol{\beta} \text { Alatrz })_{3}\right]\left(\mathrm{CF}_{3} \mathrm{SO}_{3}\right)_{2}(\mathbf{1})$ was found to exhibit a similar spin transition curve however much temperature was increased

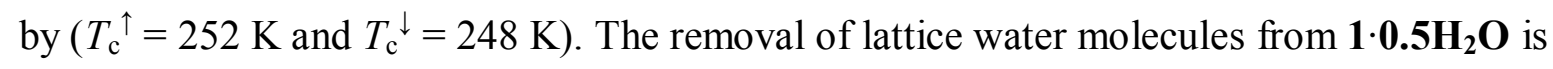
not accompanied by a change of the morphology and of the space group, and the chain 
character is preserved. However, an internal pressure effect stabilizing the low-spin state is evidenced.

Keywords: spin crossover; aminoacid triazoles; iron(II); coordination polymers

\section{Introduction}

Bistable molecular systems, particularly materials exhibiting captivating scenario of spin crossover (SCO) [1], are versatile switchable units in the thriving field of molecular electronics [2]. In a typical SCO material, the electron repositioning via singlet-quintet transitions is substantiated to be technologically significant [2]. Indeed, the reversible electron transfer from a diamagnetic low-spin (LS, ${ }^{1} \mathrm{~A}_{\mathrm{g}}$ ) state to a thermally populated paramagnetic high-spin ( $\mathrm{HS},{ }^{5} \mathrm{~T}_{2 \mathrm{~g}}$ ) state is recognized as an entropy driven process and could be addressed thermally, optically, electrically and under pressure/shock with highly profound spectroscopic, optical, magnetic, dielectric readout signal [3]. In the solid state, the presence of intra and intermolecular interactions acts as communication media between iron centers promoting cooperative first order spin transitions leading to a large memory domain [4] that can be suitable for potential applications [5]. Indeed, a SCO compound meeting display and data processing requirements would, in addition, have a good shelf life and an easily detectable optical response, and would ideally operate near room temperature [6,7].

Applications envisioned in these fields largely depend on molecular conformations precursors adopt during the coordination process which directs structure-properties relationships. In some cases, magnetic properties can even be modified by a structural perturbation as demonstrated on a 1D polyelectrolyte system [8-11]. Our interest in amino acid derivatization was fuelled by promising results shown by 1,2,4-triazole-carboxylate derivatives in synthetic chemistry [12], spin crossover area [13], nanoporous MOFs [14], biological interest in several metallo-proteases [15] and 'soft' sacrificial precursors to produce $\mathrm{CdO}$ with shape and phase selectivity [16]. As a continuation of our work on amino acid functionalization, [12] ethyl-4H-1,2,4-triazol-4-yl-acetate was used as a prospective precursor for magnetic sensors [13]. Here we introduce a new tailored 4-R-1,2,4-triazole from $\beta$-amino-acid, namely 4H-1,2,4-triazol-4-yl-propionate ( $\beta$ Alatrz) (Chart 1$)$. The reason for introducing $\beta$-Alanine ethyl ester substituted on the 4 position of a 1,2,4-triazole core was to use an appropriate length of substituent which compromises the distance between 1D chains in complexes which can introduce supramolecular interactions with $\mathrm{H}$-acceptors substituent. Thus, the spin transition (ST) properties of two one-dimensional $\mathrm{Fe}^{\mathrm{II}}$ chains, $\left[\mathrm{Fe}(\boldsymbol{\beta} \text { Alatrz })_{3}\right]\left(\mathrm{CF}_{3} \mathrm{SO}_{3}\right)_{2} \cdot 0.5 \mathrm{H}_{2} \mathrm{O}\left(\mathbf{1} \cdot \mathbf{0 . 5} \mathbf{H}_{2} \mathrm{O}\right)$ and its dehydrated form, $\left[\mathrm{Fe}(\text { Alatrz })_{3}\right]\left(\mathrm{CF}_{3} \mathrm{SO}_{3}\right)_{2}(\mathbf{1})$ were studied. 
Chart 1. Molecular structure of (a) ethyl 4H-1,2,4-triazol-4-yl-propionate ( $\beta$ Alatrz); and (b) complex $\left[\mathrm{Fe}(\boldsymbol{\beta} \text { Alatrz })_{3}\right]^{2+}$.

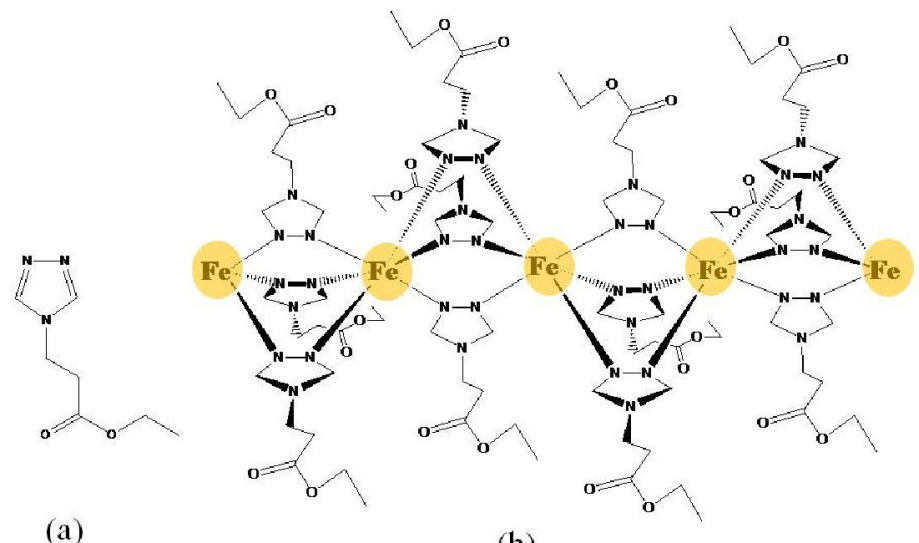

(b)

\section{Results and Discussion}

\subsection{Preparation and Characterization of $1 \cdot 0.5 \mathrm{H}_{2} \mathrm{O}$ and $\mathbf{1}$}

The transamination reaction used in the synthesis of ethyl-4H-1,2,4-triazol-4-yl-acetate and 4H-1,2,4-triazol-4-yl acetic acid [12] proved to be a good synthetic strategy to build a $\beta$-amino-acid triazole. The synthetic route, starting with $\beta$-Alanine ethyl ester hydrochloride and $N, N$-Dimethylformamide-azine, helped us to obtain a new molecule, $\boldsymbol{\beta}$ Alatrz, with a good yield. The synthesis time is relatively longer than the synthesis of previous ligands and the final product had to be purified by "flash" column chromatography.

A $1 \mathrm{D}$ coordination polymer was obtained as a white powder by reaction of the corresponding $\mathrm{Fe}^{\mathrm{II}}$ inorganic precursor, prepared in air, $\left[\mathrm{Fe}\left(\mathrm{H}_{2} \mathrm{O}\right)_{6}\right]\left(\mathrm{CF}_{3} \mathrm{SO}_{3}\right)_{2}$ [17] with a methanolic solution of $\boldsymbol{\beta}$ Alatrz. This complex was successfully characterized by elemental analysis, TGA-DTA analyses, atomic absorption (AAS), X-Ray powder diffraction, IR, Raman, SEM, DSC, SQUID magnetometry and ${ }^{57} \mathrm{Fe}$ Mössbauer spectroscopy. The thermogravimetric and elemental analyses reveal the presence of guest water molecules, affording the following general formula $\left[\mathrm{Fe}(\boldsymbol{\beta} \mathbf{A l a t r z})_{3}\right]\left(\mathrm{CF}_{3} \mathrm{SO}_{3}\right)_{2} \cdot 0.5 \mathrm{H}_{2} \mathrm{O}$

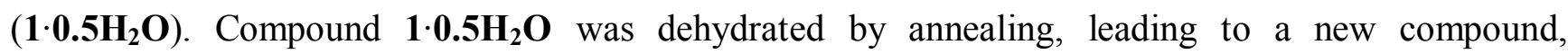
$\left[\mathrm{Fe}(\boldsymbol{\beta} \text { Alatrz })_{3}\right]\left(\mathrm{CF}_{3} \mathrm{SO}_{3}\right)_{2}$ (1), which was also characterized to reveal the influence of solvent molecules on the spin state. $\mathbf{1} \cdot \mathbf{0 . 5 H _ { 2 }} \mathrm{O}$ presents a rather crystalline character as revealed from X-ray powder diffraction (XRPD) patterns (Figure 1).

This result is also illustrated by the SEM analysis with blocks of hexagonal shape of about $2 \mu \mathrm{m}$ widths (Figure 2). FT-IR and Raman analyses were performed: (i) to confirm the identity of the ligand framework before and upon complexation as the ester functionality is susceptible to hydrolysis; (ii) to ascertain the coordination mode of iron to the ligand and the presence of the trifluoromethane sulfonate in the crystal lattice (Figure 3).

Two sharp IR bands at $3,118(\mathrm{~s})$ and $2,983(\mathrm{~m}) \mathrm{cm}^{-1}$ of $\boldsymbol{\beta A l a t r z}$, are assigned to the $\mathrm{vCH}_{2}$ modes [18]. The carboxylic group of ester shows two stretching vibrations corresponding to $(\mathrm{C}=\mathrm{O})$ and $(\mathrm{C}-\mathrm{O})$ at $1,728(\mathrm{~s})$ and $1,205(\mathrm{~s}) \mathrm{cm}^{-1}$, respectively, which are almost unchanged $\left(1,732\right.$ and $\left.1,212 \mathrm{~cm}^{-1}\right)$ in $\mathbf{1} \cdot \mathbf{0 . 5} \mathrm{H}_{2} \mathrm{O}$ ruling out the possible ester hydrolysis and also confirming the non-involvement of 
carboxylic ester group in coordination. For $\beta$ Alatrz, the band assigned to ring torsion of triazole at $v=634(\mathrm{~m}) \mathrm{cm}^{-1}$, the $v_{\mathrm{C}=\mathrm{N}}$ stretching vibration at $1,535(\mathrm{~m}) \mathrm{cm}^{-1}$ and the $\mathrm{N}-\mathrm{N}$ stretching band at $v=1,022(\mathrm{~s}) \mathrm{cm}^{-1}$, are all shifted upon complexation in $\mathbf{1 \cdot 0 . 5 \mathbf { H } _ { 2 }} \mathbf{O}$ to $632 \mathrm{~cm}^{-1}, v_{\mathrm{C}=\mathrm{N}}=1,560 \mathrm{~cm}^{-1}$, and $v_{\mathrm{N}-\mathrm{N}}=1,028 \mathrm{~cm}^{-1}$, respectively.

These values confirm the coordination of the iron to the 1,2,4-triazole ring [19,20]. Indeed, the characteristic bands of the ligand are not only present in the spectra of the complexes but are also shifted towards larger wave numbers, from 3 to $15 \mathrm{~cm}^{-1}$, respectively. This energy increase is due to the deformation of the ligand upon coordination of the metal, the ligand molecule being indeed more constrained to perform vibration and twisting movements [19,21].

Figure 1. Top: X-ray powder diffraction pattern of 1, (thermally treated compound in

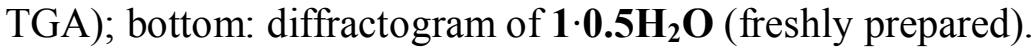

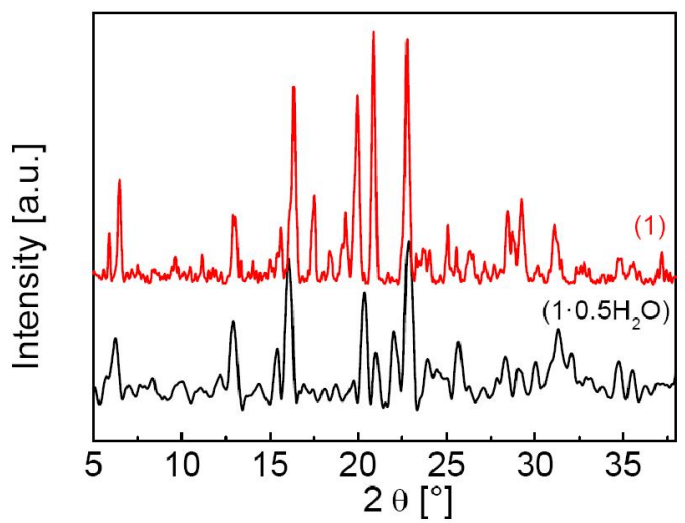

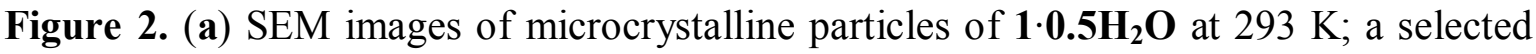
crystal is highlighted in red; and (b) SEM analysis of $\mathbf{1}$ confirms the framework integrity preservation after thermal treatment.

(a)
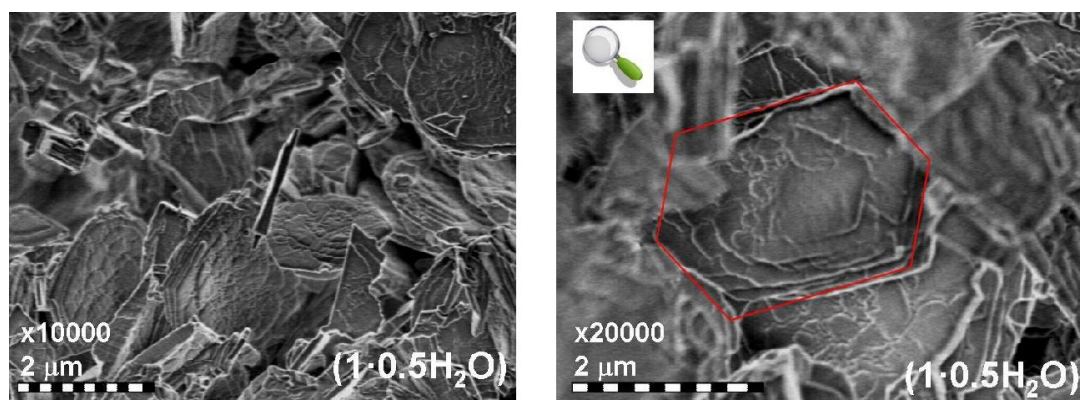

(b)

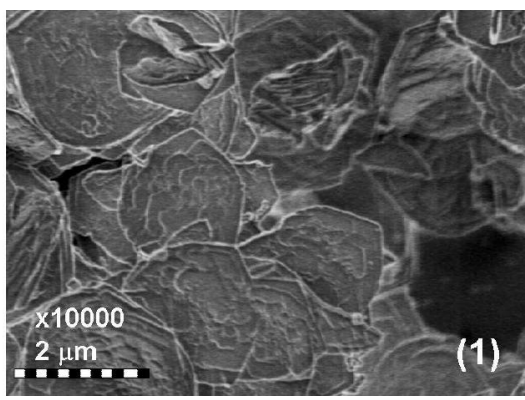




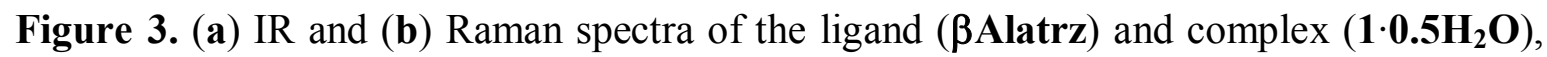
over the range $400-2,100 \mathrm{~cm}^{-1}$ and $180-2,000 \mathrm{~cm}^{-1}$, respectively. The IR and Raman spectra for 1.0.5 $\mathrm{H}_{2} \mathrm{O}$ and $\mathbf{1}$ (not shown) are identical, except around $3,500 \mathrm{~cm}^{-1}$ with $v_{(\mathrm{O}-\mathrm{H})}$ of water molecules clearly identified for $\mathbf{1} \cdot \mathbf{0 . 5} \mathrm{H}_{2} \mathrm{O}$.

(a)

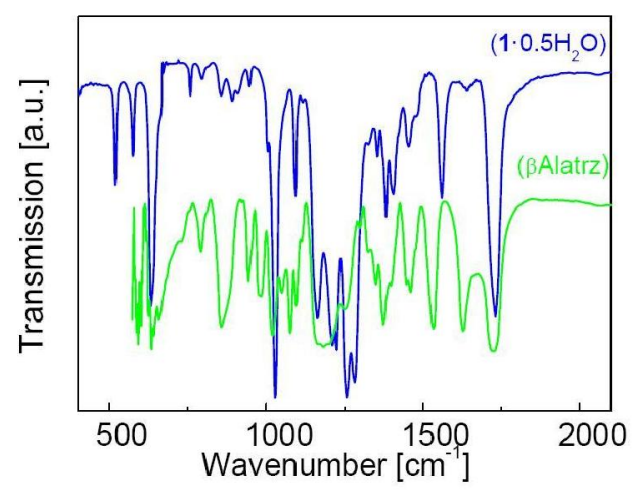

(b)

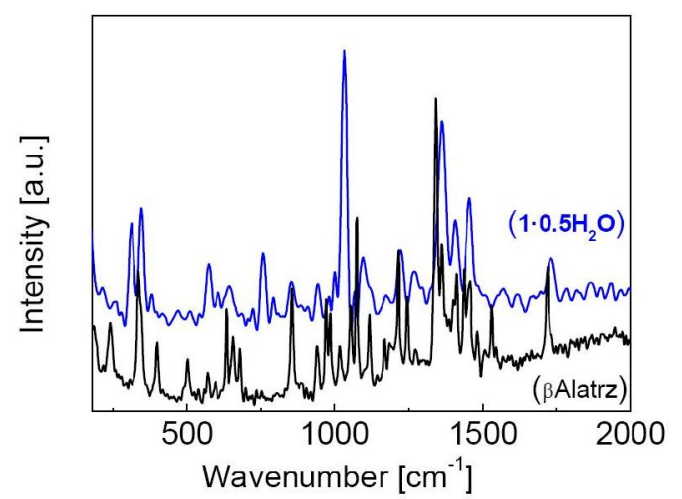

For a better understanding of the molecular structure of these ligands, Raman spectra were also collected (Figure 3). The band present at $1,728 \mathrm{~cm}^{-1}$ for $\beta$ Alatrz is assigned to a $\mathrm{C}=\mathrm{O}$ vibration. In complexes this band is retained and appears around $1,732 \mathrm{~cm}^{-1}$. The $\mathrm{C}-\mathrm{C}$ stretching is also active in Raman as a medium band at $1,098 \mathrm{~cm}^{-1}$ for $\beta$ Alatrz and appears in the same wavenumber in $\mathbf{1 \cdot 0 . 5 H _ { 2 }} \mathbf{O}$. Presence of the monovalent counter-anion is also confirmed by IR and Raman: $I R\left(\mathrm{~cm}^{-1}\right)$ $\mathrm{v}_{(\mathrm{S}-\mathrm{O})} \sim 1,283(\mathrm{~s}),\left(\mathbf{1} \cdot \mathbf{0 . 5} \mathbf{H}_{2} \mathbf{O}\right)$; Raman $\left(\mathrm{cm}^{-1}\right) \mathrm{v}_{(\mathrm{S}-\mathrm{O})} \sim 1,034(\mathrm{~s}), 760(\mathrm{~m})\left(\mathbf{1 \cdot 0 . 5 H _ { 2 }} \mathbf{O}\right)[22] .{ }^{57} \mathrm{Fe}$ Mössbauer

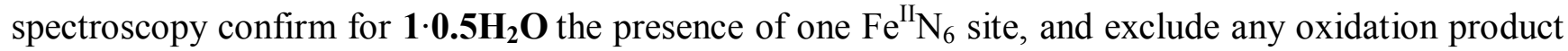
of iron. These spectroscopic data support a linear chain structure with $\mathrm{Fe}^{\mathrm{II}}$ ions linked by triple $N 1, N 2-1,2,4$-triazole bridges [23,24].

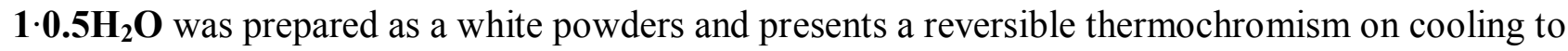
pink (Figure 4). These colors depend on the spin state of the Fe ${ }^{\mathrm{II}}$ centers, as the ST involves a change in the electronic configuration which modifies the absorption spectrum of the complex.

Figure 4. UV-Vis diffuse reflectance spectrum of $\mathbf{1} \cdot \mathbf{0 . 5 H _ { 2 }} \mathbf{O}$ showing $d-d$ transitions at $293 \mathrm{~K}$.

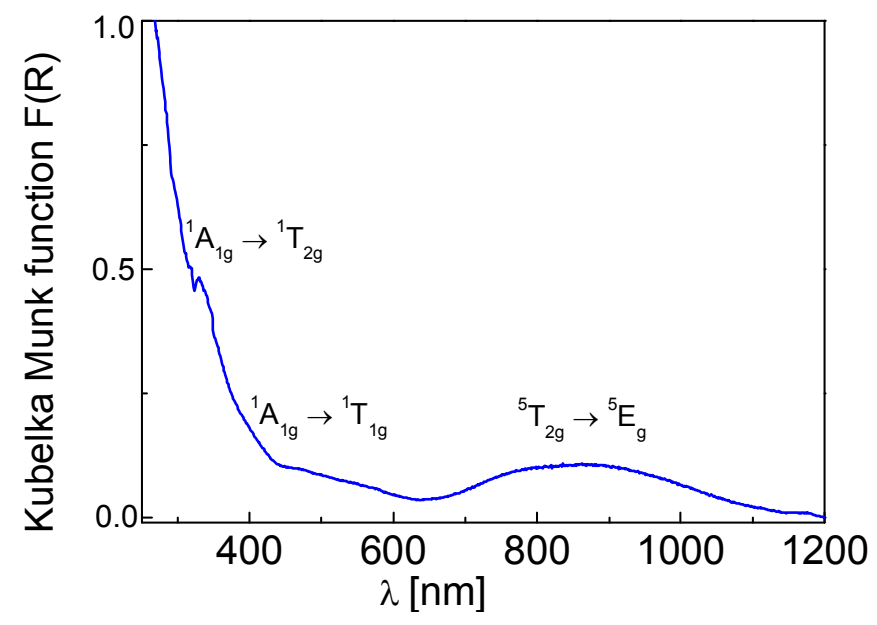


The white color of $\mathbf{1 \cdot 0 . 5 H _ { 2 }} \mathrm{O}$, is due to the location of the spin-allowed lowest energy d-d transition, ${ }^{5} \mathrm{~T}_{2 \mathrm{~g}} \rightarrow{ }^{5} \mathrm{E}_{\mathrm{g}}$, for the HS sites in the near infrared region $\left(\sim 11,500 \mathrm{~cm}^{-1}\right)[25,26]$. Two supplementary bands, corresponding to the ${ }^{1} \mathrm{~A}_{1 \mathrm{~g}} \rightarrow{ }^{1} \mathrm{~T}_{1 \mathrm{~g}}$ and ${ }^{1} \mathrm{~A}_{1 \mathrm{~g}} \rightarrow{ }^{1} \mathrm{~T}_{2 \mathrm{~g}} \mathrm{~d}-\mathrm{d}$ transitions of LS Fe ${ }^{\mathrm{II}}$ sites are observed at $\sim 18,727 \mathrm{~cm}^{-1}$ and $\sim 30,300 \mathrm{~cm}^{-1}$, respectively suggesting that some proportion of $\mathrm{Fe}^{\mathrm{II}}$ may be in the LS state at room temperature. The ligand field strengths for the HS and the LS state, given by equations $10 \mathrm{D}_{\mathrm{q}}{ }^{\mathrm{HS}}=\mathrm{E}\left({ }^{5} \mathrm{E}\right)-\mathrm{E}\left({ }^{5} \mathrm{~T}_{2}\right)$ and $10 \mathrm{D}_{\mathrm{q}}{ }^{\mathrm{LS}}=\mathrm{E}\left({ }^{1} \mathrm{~T}\right)-\mathrm{E}\left({ }^{1} \mathrm{~A}_{1}\right)+\left(\mathrm{E}\left({ }^{1} \mathrm{~T}_{2}\right)-\mathrm{E}\left({ }^{1} \mathrm{~T}_{1}\right)\right) / 4,[25,26]$ allowed us to estimate $10 \mathrm{D}_{\mathrm{q}}^{\mathrm{HS}}$ and $10 \mathrm{D}_{\mathrm{q}}^{\mathrm{LS}}$ to be approximately $11,500 \mathrm{~cm}^{-1}$ and $26,302 \mathrm{~cm}^{-1}$, respectively. These values are characteristic for SCO complexes $[25,26]$. Presence of LS state at room temperature has been confirmed by ${ }^{57} \mathrm{Fe}$ Mössbauer spectroscopy (vide infra).

The reversibility of the rehydration/dehydration process within a given framework structure with the change of crystallinity can play an important role on the SCO properties [27]. This process was

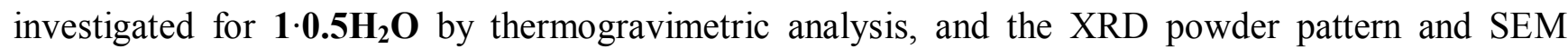
imaging recorded after annealing treatment. The sample was first deposited in a crucible and slowly heated at $1 \mathrm{~K} / \mathrm{min}$ in air atmosphere (air flow $130 \mathrm{~mL} / \mathrm{min}$ ) to the temperature of complete dehydration $(390 \mathrm{~K})$ leading to $\mathbf{1}$. After a short standby period, the sample was cooled $(1 \mathrm{~K} / \mathrm{min})$ slowly to reach room temperature revealing no rehydration. Thus the dehydration-rehydration process is irreversible and 1 is air stable which will ease any further physical studies on this compound. Comparison of the powder XRD patterns (Figure 1) and SEM images (Figure 2) of $\mathbf{1 . 0 . 5} \mathbf{H}_{\mathbf{2}} \mathbf{O}$ and $\mathbf{1}$ allow to exclude any framework rupture. Indeed, these two compounds are isostructural, 1 showing higher peak intensities indicating a better crystalline character. No deterioration is observed by SEM.

\subsection{SQUID Magnetometry}

The temperature dependent magnetic properties of $\mathbf{1 \cdot 0 . 5 H _ { 2 }} \mathrm{O}$ and $\mathbf{1}$ were determined by temperature-dependent susceptibility measurements using a SQUID magnetometer operating at 1000 Oe (Figure 5).

For complex $\mathbf{1} \cdot \mathbf{0 . 5} \mathbf{H}_{2} \mathrm{O}, \chi_{\mathrm{M}} T$ is $3.10 \mathrm{~cm}^{3} \mathrm{~K} \mathrm{~mol}^{-1}$ at $300 \mathrm{~K}$, which is in the region expected for an $\mathrm{Fe}^{\mathrm{II}}$ complex essentially in the HS state, with a small \% of LS species. Upon cooling, $\chi_{\mathrm{M}} T$ remains almost constant until $240 \mathrm{~K}$ where it drops sharply to $T_{c}^{\downarrow}=228 \mathrm{~K}^{\downarrow}$ down to $\sim 0.14 \mathrm{~cm}^{3} \mathrm{~K} \mathrm{~mol}^{-1}$ at $77 \mathrm{~K}$, which is typical for a diamagnetic $\mathrm{Fe}^{\mathrm{II}}$ complex with possibly a few HS ions.

Figure 5. Thermal variation of $\chi_{\mathrm{M}} T$ of $\mathbf{1} \cdot \mathbf{0 . 5} \mathbf{H}_{2} \mathrm{O}$ (depicted in red) and $\mathbf{1}$ (depicted in blue).

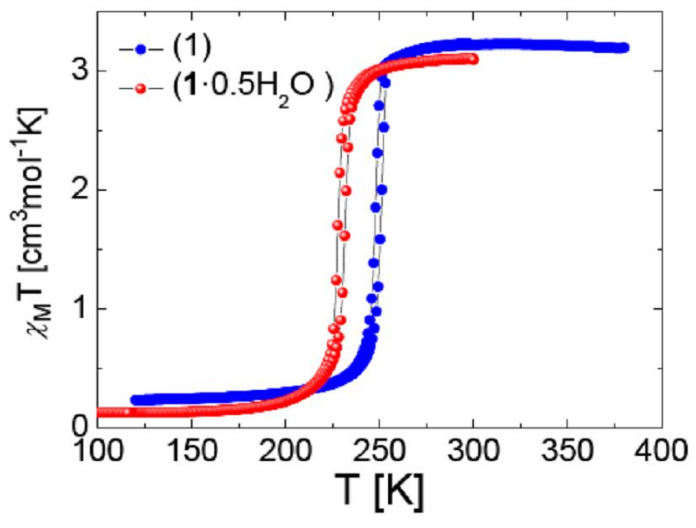


Upon warming, the $\chi_{\mathrm{M}} T$ curve differs slightly revealing a small hysteresis width $(4 \mathrm{~K})$ at $T_{c}^{\uparrow}=232 \mathrm{~K}$ for this very sharp spin transition. An hysteretic behavior of width $4 \mathrm{~K}$ was observed too for 1 with a ST shifted upwards $\left(T_{c}^{\downarrow}=248 \mathrm{~K}\right.$ and $\left.T_{c}^{\uparrow}=252 \mathrm{~K}\right)$. The same curve shape is observed too which confirms the preservation of the 1D chain character [27] and does not support the appearance of a structural phase transition following the annealing process. The stabilization of the LS state upon water release is uncommon for this family of complexes [28] and was only observed for the 1D chain compounds $\left[\mathrm{Fe}\left(4-\left(2^{\prime} \text {-hydroxyethyl }\right)-1,2,4 \text {-triazole }\right)_{3}\right](\text { anion })_{2} \cdot \mathrm{nH}_{2} \mathrm{O}\left(\right.$ anion $=\mathrm{ClO}_{4}{ }^{-}, \mathrm{n}=2,0$; anion $=\mathrm{I}^{-}$, $\mathrm{n}=1,0)$ [29], [Fe(4-amino-1,2,4-triazole) 3 (anion) $\mathrm{nH}_{2} \mathrm{O}$ (anion $=\mathrm{TiF}_{6}{ }^{2-}, \mathrm{n}=1,0.5$; anion $=\mathrm{ZrF}_{6}{ }^{2-}$, $\mathrm{n}=0.5,0)[23]$ as well as for $\left[\mathrm{Fe}(\text { ethyl-4H-1,2,4-triazol-4-yl-acetate })_{3}\right]\left(\mathrm{ClO}_{4}\right)_{2} \cdot \mathrm{nCH}_{3} \mathrm{OH}(\mathrm{n}=1,0)$ but with methanol as solvent [13]. The effect of the release of non-coordinated solvent molecules on the spin state can be translated here as an internal positive pressure effect $[5,23]$.

\section{3. ${ }^{57}$ Fe Mössbauer Spectroscopy}

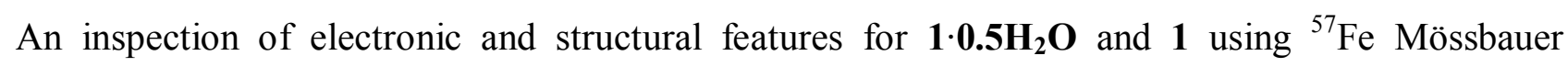
spectroscopy was undertaken over the temperature range 77-300 K (Figure 6). At $77 \mathrm{~K}$, the spectrum

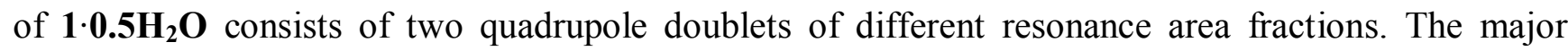
quadrupole doublet with isomer shift $\delta^{L S}=0.51(2) \mathrm{mm} / \mathrm{s}$ and quadrupole splitting, $\Delta E_{Q}{ }^{L S}=0.23(2)$ $\mathrm{mm} / \mathrm{s}$ correspond to the LS state of $\mathrm{Fe}^{\mathrm{II}}$. The presence of an LS quadrupole splitting stems from a lattice contribution to the electric field gradient and therefore reveals a distorted character for the LS octahedron as expected within a chain, where constraints may not be negligible [30]. Another doublet, corresponding to $\mathrm{HS} \mathrm{Fe}{ }^{\mathrm{II}}$ ions of weaker population $(7 \%)$, with parameters $\left(\delta^{H S}=1.14(1) \mathrm{mm} / \mathrm{s}\right.$ and $\Delta E_{Q}{ }^{H S}=3.15(2) \mathrm{mm} / \mathrm{s}$ ) confirms the incomplete nature of the $\mathrm{ST}$ at $77 \mathrm{~K}$. Upon warming to $300 \mathrm{~K}$, the intensity of the HS doublet slowly increases to $8 \%$ at $225 \mathrm{~K}$, after which it increases dramatically to $87.5 \%$ at $300 \mathrm{~K}$, confirming an incomplete thermally induced LS $\rightarrow$ HS conversion for a single Fe ${ }^{\mathrm{II}}$ site. The presence of LS ions at room temperature could be related to crystal defects or end of chains. The hysteresis effect is clearly evidenced at $225 \mathrm{~K}$ (Figure 6a).

At $80 \mathrm{~K}$, the spectrum of 1 shows a single LS quadrupole doublet $\left(\delta^{\mathrm{LS}}=0.52(1) \mathrm{mm} / \mathrm{s}\right.$ and $\Delta E_{Q}{ }^{\mathrm{LS}}=0.25(2) \mathrm{mm} / \mathrm{s}$ ) indicating a complete spin transition. The compound remains mostly in the LS state on warming up to $250 \mathrm{~K}$, after which a second quadrupole doublet attributed to $\mathrm{HS} \mathrm{Fe}^{\mathrm{II}}$ ions grows in intensity (e.g., at $297 \mathrm{~K}, \delta^{\mathrm{HS}}=1.03(1) \mathrm{mm} / \mathrm{s}$ and $\Delta E_{Q}{ }^{\mathrm{HS}}=2.75(1) \mathrm{mm} / \mathrm{s}$ ). The asymmetry of the lines observed in the HS state is attributed to a texture effect. Upon cooling to low temperature, the reverse situation is observed with a clear hysteresis effect at $250 \mathrm{~K}$ (Figure $6 \mathrm{~b}$ ).

The isomer shift $\left(\delta^{\mathrm{LS}} \sim 0.51(1) \mathrm{mm} / \mathrm{s}\right.$ at $77-80 \mathrm{~K}$ and $\Delta E_{Q}{ }^{\mathrm{HS}}=1.03(1) \mathrm{mm} / \mathrm{s}$ at $\left.297-300 \mathrm{~K}\right)$ is not affected by the dehydration process which indicates that non coordinated water molecules are not $\mathrm{H}$-bonded to the triazole ligand [31], but should be located at a remote position to the complex in the crystal lattice, either isolated or hydrogen bonded to the sulfonate group of the non coordinated anions. Their releases have no influence on the structural organization as demonstrated by the similarity in $\mathrm{X}$-ray powder diffraction data. However, a clear influence on the transition temperatures, i.e., on the respective energy levels of the HS and LS states [25], has been detected. 
Figure 6. ${ }^{57} \mathrm{Fe}$ Mössbauer spectra cycles for $\mathbf{1 \cdot 0 . 5 H _ { 2 }} \mathbf{O}$ (a) and $\mathbf{1}$ (b) at selected temperatures. Grey and dark grey correspond to the high-spin (HS) and low-spin (LS) doublets, respectively.

(a)
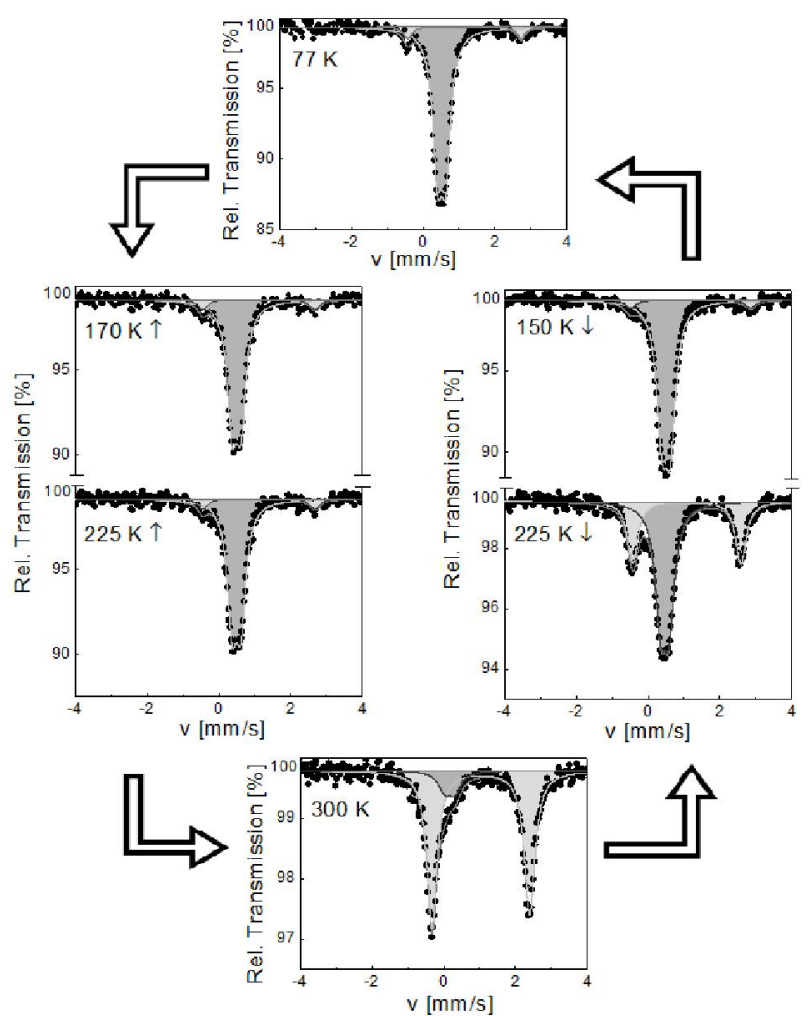

(b)

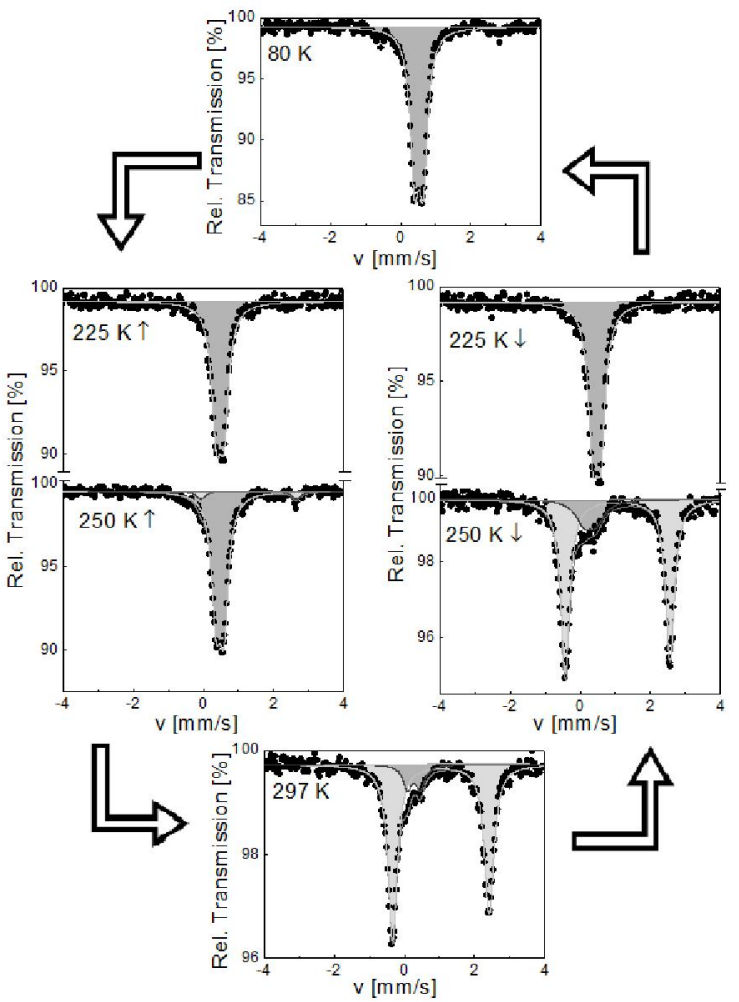

\subsection{Differential Scanning Calorimetry}

Compound 1.0.5 $\mathrm{H}_{2} \mathrm{O}$ and 1 were investigated by differential scanning calorimetry over the temperature range $100-300 \mathrm{~K}$, at $10 \mathrm{~K} / \mathrm{min}$ for both cooling and heating modes (Figure 7).

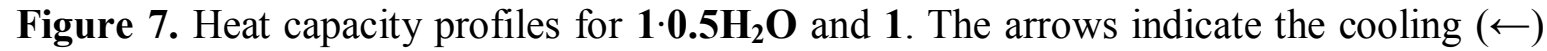
and warming $(\rightarrow)$ modes, respectively.

(a)

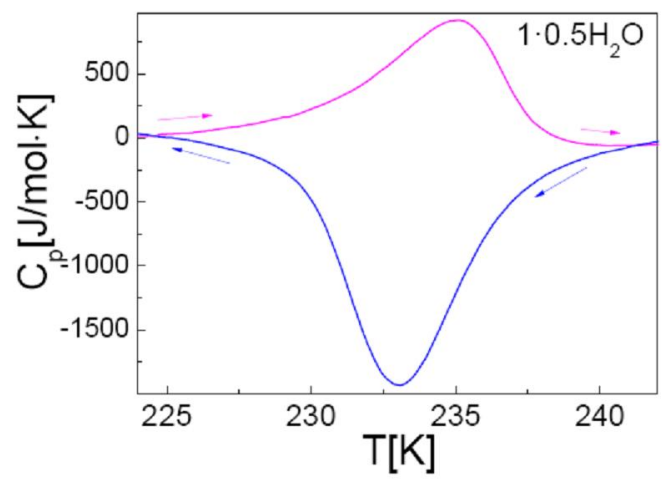

(b)

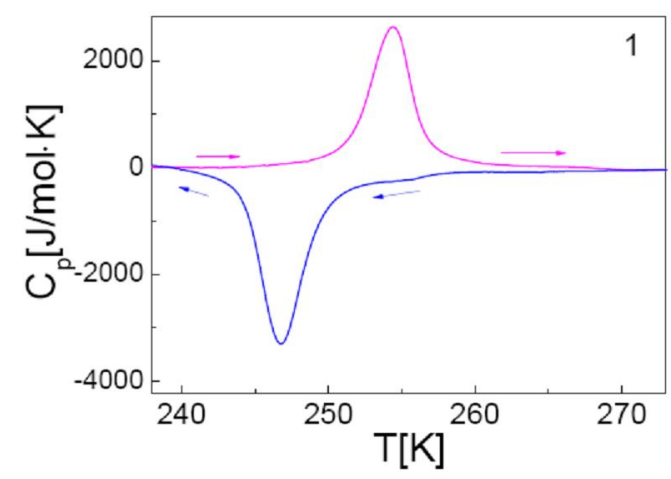


An endothermic peak is observed on warming for $\mathbf{1} \cdot \mathbf{0 . 5} \mathbf{H}_{2} \mathbf{O}$ at $T_{\max }{ }^{\uparrow}=235(1) \mathrm{K}$ and an exothermic peak is recorded at $T_{\max }{ }^{\downarrow}=233(1) \mathrm{K}$, on cooling. These peaks correspond to a first-order phase transition in agreement with the transition temperatures determined by both SQUID and Mössbauer spectroscopy. The enthalpy and entropy variations associated to the active SCO centers are $\Delta H=12(2) \mathrm{kJ} / \mathrm{mol}$ and $\Delta S=51(2) \mathrm{J} / \mathrm{mol} / \mathrm{K}$. A similar profile, although with more abrupt peaks, was detected for 1 with phase transitions shifted upwards to $T_{\max }{ }^{\uparrow}=254(1) \mathrm{K}$ and $T_{\max }{ }^{\downarrow}=247(1) \mathrm{K}$. The peaks are separated by a narrow temperature domain, which is indicative of the presence of a hysteresis loop. The enthalpy and entropy associated to the ST, considering only the switching sites, were derived as follows: $\Delta H=13(1) \mathrm{kJ} / \mathrm{mol}$ and $\Delta S=59(2) \mathrm{J} / \mathrm{mol} / \mathrm{K}$.

\section{Experimental Section}

\subsection{Chemicals}

All reagents and solvents were used as received from commercial source: benzene (Fluka analytical), Methanol (VWR), $\mathrm{SOCl}_{2}$ (Sigma-Aldrich), glycine ethyl ester hydrochloride (ACROS), $\mathrm{CF}_{3} \mathrm{SO}_{3} \mathrm{H}$ (ACROS), Fe powder (Merck). Ethyl 4H-1,2,4-triazol-4-yl-propionate ( $\beta$ Alatrz) were prepared by a similar method described in reference [12].

\subsubsection{Ethyl 4H-1,2,4-Triazol-4-yl-Propionate ( $\beta$ Alatrz)}

$\mathrm{N}, \mathrm{N}$-Dimethylformamide azine dihydrochloride (I) and its free base (II) were obtained following the reported method [12]. The free base was recrystallized twice from benzene with charcoal and used in transamination reactions [12]. To a suspension of $\beta$-alanine ethyl ester hydrochloride (3 $\mathrm{g}$, $19.53 \mathrm{mmol})$ in benzene $(100 \mathrm{~mL})$ at approx. $60{ }^{\circ} \mathrm{C}$ was added solid II $(2.14 \mathrm{~g}, 15.04 \mathrm{mmol})$ with stirring, obtaining a transparent yellow solution. The mixture was refluxed then $\left(\right.$ at $\left.130{ }^{\circ} \mathrm{C}\right)$ for $93 \mathrm{~h}$ with vigorous stirring. The reaction was monitored by NMR analysis at interval of time. Finally, the solvent was removed under vacuum and a chromatographic purification $\left(\mathrm{SiO}_{2}, \mathrm{CH}_{2} \mathrm{Cl}_{2} \rightarrow 5 \%\right.$ isopropanol in $\mathrm{CH}_{2} \mathrm{Cl}_{2}$ ) of the yellow oil gave pale yellow oil. Yield $2 \mathrm{~g}(60 \%)$. ${ }^{1} \mathrm{H} \mathrm{NMR} \mathrm{(300} \mathrm{MHz,}$ $\left.\mathrm{CDCl}_{3}, 298 \mathrm{~K}\right): \delta=8.25(\mathrm{~s}, 2 \mathrm{H}), 4.34(t, 3 \mathrm{H}, J=6.17 \mathrm{~Hz}), 4.14(d d, 2 \mathrm{H}, J=7.10 \mathrm{~Hz} \& 7.15 \mathrm{~Hz}), 2.78$ $(t, 2 \mathrm{H}, J=6.17 \mathrm{~Hz}), 1.23(t, 3 \mathrm{H}, J=7.16 \mathrm{~Hz}) \cdot{ }^{13} \mathrm{C} \mathrm{NMR}\left(300 \mathrm{MHz}, \mathrm{CDCl}_{3} 298 \mathrm{~K}\right): \delta=170.1,143$, 61.6, 40.6, 35.5, 14.1. MS: $m / z=170.03\left(\mathrm{M}+\mathrm{H}^{+}\right)$. FTIR (thin film from $\mathrm{CH}_{2} \mathrm{Cl}_{2}$ on ZnSe HATR through plate, $\left.\mathrm{cm}^{-1}\right): 3,118(\mathrm{~s}), 1,728(\mathrm{vs}), 1,535(\mathrm{~s}), 1,236(\mathrm{~s}), 1,205(\mathrm{~s}), 1,186(\mathrm{~s}), 1,022(\mathrm{~m}), 637(\mathrm{~s})$. Anal. Calcd. for $\mathrm{C}_{7} \mathrm{H}_{11} \mathrm{~N}_{3} \mathrm{O}_{2}$ (169.18 g/mol): C, 49.70, H, 6.55, N, 24.84; Found C, 49.7, H, 6.81, N, 22.61.

\subsection{2. $\left[\mathrm{Fe}(\beta \text { Alatrz })_{3}\right]\left(\mathrm{CF}_{3} \mathrm{SO}_{3}\right)_{2} \cdot 0.5 \mathrm{H}_{2} \mathrm{O}\left(\mathbf{1} \cdot \mathbf{0 . 5} \mathbf{H}_{2} \mathbf{O}\right)$}

$\left[\mathrm{Fe}\left(\mathrm{H}_{2} \mathrm{O}\right)_{6}\right]\left(\mathrm{CF}_{3} \mathrm{SO}_{3}\right)_{2}$ was first synthesized as a very pale green powder using a described procedure [16], starting with an aqueous solution $(1 \mathrm{~mL})$ containing an iron powder in excess $(2 \mathrm{~g})$ carefully mixed to triflic acid $(5 \mathrm{~mL}, 56.5 \mathrm{mmol})$. Yield: $9.8 \mathrm{~g}, 74 \%$. $\left[\mathrm{Fe}\left(\mathrm{H}_{2} \mathrm{O}\right)_{6}\right]\left(\mathrm{CF}_{3} \mathrm{SO}_{3}\right)_{2}(183.2 \mathrm{mg}$, $0.396 \mathrm{mmol})$ was dissolved in $\mathrm{CH}_{3} \mathrm{OH}(5 \mathrm{~mL})$ with a pinch of ascorbic acid and added to the above solution of $\beta$ Alatrz (205.7 mg, $1.216 \mathrm{mmol}$ ) dissolved in $\mathrm{CH}_{3} \mathrm{OH}(5 \mathrm{~mL})$. The mixture was stirred for $15 \mathrm{~min}$ at room temperature, after which a white precipitate was obtained. It was filtered, washed with 
$\mathrm{CH}_{3} \mathrm{OH}(2 \mathrm{~mL})$ and dried in air. Yield: $265.9 \mathrm{mg}, 75.4 \%$. Anal. for $\mathrm{FeC}_{23} \mathrm{H}_{34} \mathrm{~N}_{9} \mathrm{O}_{12.5} \mathrm{~F}_{6} \mathrm{~S}_{2}$ (870.54 g/mol): calcd. C, 31.73; H, 3.94; N, 14.48; F, 13.09; S, 7.37; Fe, 6.42\%. Found C, 31.64; H, 3.76; N, 14.41; F, 12.12; S, 6.37; Fe, 6.59\%. IR (KBr, $\left.\mathrm{cm}^{-1}\right): v(\mathrm{C}=\mathrm{O}) \sim 1,732(\mathrm{vs}), v(\mathrm{C}-\mathrm{O}) \sim 1,211$, $1,093(\mathrm{~s}), \quad v(\mathrm{C}=\mathrm{N}) \sim 1,560(\mathrm{~m}), \quad v(\mathrm{C}-\mathrm{H}$ out of plane $) \sim 1,028(\mathrm{~m}), \quad v(\mathrm{C}-\mathrm{H}$ ring torsion $) \sim 632(\mathrm{~m})$, $\mathrm{v}_{(\mathrm{S}-\mathrm{O})} \sim 1,282,1,255$ (vs, with shoulders).

\subsection{Physical Measurements}

Elemental analyses were performed at University College London (UK) and at S.C.A. CNRS Solaize (France). ${ }^{1} \mathrm{H}$ and ${ }^{13} \mathrm{C}$ NMR spectra were recorded at $300 \mathrm{MHz}$ and $75 \mathrm{MHz}$, respectively, on a Bruker AC300 instrument. The residual solvent peak was used as internal reference. Mass spectral data were obtained on Thermo Finnigan LCQ Ion trap spectrometer (APCI mode). HRMS were carried out on a Micromass Q TOF 2 spectrometer in ESI mode, detecting positive mode. Raman spectra with $1,064 \mathrm{~nm}$ excitation were recorded between 2,300 to $400 \mathrm{~cm}^{-1}$ with a Bruker RFS 100/s FT-Raman spectrometer $(I=200 \mathrm{~mW})$ at r.t using a diode-pumped, air-cooled Nd:YAG laser as the excitation source. IR spectra were collected on a Shimadzu FTIR-84005 spectrometer using $\mathrm{KBr}$ pellets. Thermogravimetric analyses (TGA) were performed in air $(100 \mathrm{~mL} / \mathrm{min})$ at the heating rate of $1{ }^{\circ} \mathrm{C} / \mathrm{min}$ from $293 \mathrm{~K}$ to $400 \mathrm{~K}$ using a Mettler Toledo TGA/SDTA 851e analyzer. Diffuse reflectance spectra on solids were recorded with a CARY 5E spectrophotometer using polytetrafluoroethylene as a reference. Powder X-ray diffraction patterns were recorded on a Siemens D5000 counter diffractometer working with $\mathrm{Cu}-\mathrm{K} \alpha$ radiation and operating at room temperature. The samples were mounted on the support with silicon grease. ${ }^{57} \mathrm{Fe}$ Mössbauer spectra were recorded in transmission geometry over the temperature range (78-300 K) with a conventional Mössbauer spectrometer equipped with a Cyclotron $\mathrm{Ltd}{ }^{57} \mathrm{Co}(\mathrm{Rh})$ radioactive source operating at room temperature. The samples were sealed in aluminum foil and mounted on an Oxford nitrogen bath cryostat. The spectra were fitted to the sum of Lorentzians by a least-squares refinement using Recoil 1.05 Mössbauer Analysis Software [32]. All isomer shifts refer to $\alpha$-Fe at room temperature. Magnetic susceptibilities were measured in the temperature range 4-390 K using a MPMS-XL (7T) SQUID magnetometer. Data were corrected for magnetization of the sample holder and diamagnetic contributions, which were estimated from the Pascal constants. Differential scanning calorimetry measurements were carried out in a $\mathrm{He}_{(\mathrm{g})}$ atmosphere using a Perkin-Elmer DSC Pyris 1 instrument equipped with a cryostat and operating down to $98 \mathrm{~K}$. Aluminum capsules were loaded with $20-50 \mathrm{mg}$ of sample and sealed. The heating and cooling rates were fixed at $10 \mathrm{~K} \mathrm{~min}^{-1}$. Temperatures and enthalpies were calibrated over the temperature range of interest (298-400 K) using the solid-liquid transitions of pure In (99.99\%) [33], and the crystal-crystal transitions of pure cyclopentane ( $\geq 99 \%)$ [34], over the range 78-298 $\mathrm{K}$. Scanning electron microscopy (SEM) was performed using a Gemini Digital Scanning Microscope 982 with $1 \mathrm{kV}$ accelerating voltage with an aluminum sample holder.

\section{Concluding Remarks}

We have presented two novel Fe ${ }^{\mathrm{II}}$ 1D ST chain compounds switching in the range 225-250 $\mathrm{K}$. Release of non coordinated water molecules has a paramount effect on the LS state stabilization of $\mathbf{1 .}$ 
Its air stability and absence of solvent will ease further physical measurements, particularly using hydrostatic pressure [5] so as to shift its hysteresis loop towards the room temperature region.

\section{Acknowledgments}

We acknowledge financial support from IAP-VI (P6/17) INANOMAT, the Fonds National de la Recherche Scientifique (FNRS) (FRFC 2.4508.08, IISN 4.4507.10), a Concerted Research Action of the "Communauté Française de Belgique" allotted by the Académie Universitaire Louvain and from the European Social Fund through Sectorial Operational Program Human Resources: PRiDE (No POSDRU/89/1.5/S/57083. J. Marchand-Brynaert is a senior research associate of the F.R.S.-FNRS.

\section{References}

1. Gütlich, P.; Garcia, Y.; Goodwin, H.A. Spin crossover phenomena in Fe(II) complexes. Chem. Soc. Rev. 2000, 29, 419-427.

2. Bousseksou, A.; Molnár, G.; Salmon, L.; Nicolazzi, W. Molecular spin crossover phenomenon: Recent achievements and prospects. Chem. Soc. Rev. 2011, 40, 3313-3118.

3. Gütlich, P.; Garcia, Y.; Spiering, H. Magnetism: From Molecules to Materials, 1st ed.; Miller, J.S., Drillon, M., Eds.; Wiley-VCH: Hoboken, NJ, USA, 2003; Volume IV.

4. Weber, B.; Bauer, W.; Obel, J. An iron (II) spin-crossover complex with a $70 \mathrm{~K}$ wide thermal hysteresis loop. Angew. Chem. Int. Ed. 2008, 47, 10098-10101.

5. Garcia, Y.; Ksenofontov, V.; Gütlich P. Spin transition molecular materials: New sensors. Hyperfine Interact. 2002, 139-140, 543-551.

6. Kahn, O.; Krober, J.; Jay, C. Spin Transition molecular materials for displays and data recording. Adv. Mater. 1992, 4, 718-728.

7. Kahn, O.; Jay-Martinez, C. Spin-transition polymers: From molecular materials toward memory devices. Science 1998, 279, 44-48.

8. Bodenthin, Y.; Pietsch, U.; Möhwald, H.; Kurth, D.G. Inducing spin crossover in Metallo-supramolecular polyelectrolytes through an amphiphilic phase transition. J. Am. Chem. Soc. 2005, 127, 3110-3115.

9. Bodenthin, Y.; Pietsch, U.; Grenzer, J.; Geue, T., Möhwald, H.; Kurth, D.G. Structure and temperature behavior of metallo-supramolecular assemblies. J. Phys. Chem. B 2005, 109, 12795-12799.

10. Bodenthin, Y.; Schwarz, G.; Tomkowicz, Z.; Geue, T.; Haase, W.; Pietsch, U.; Kurth, D.G. Liquid crystalline phase transition induces spin crossover in a polyelectrolyte amphiphile complex. J. Am. Chem. Soc. 2009, 131, 2934-2941.

11. Schwarz, G.; Bodenthin, Y.; Tomkowicz, Z.; Haase, W.; Geue, T.; Kohlbrecher J.; Pietsch, U.; Kurth, D.G. Tuning the structure and the magnetic properties of metallo-supramolecular polyelectrolyte-amphiphile complexes. J. Am. Chem. Soc. 2011, 133, 547-558.

12. Naik, A.D.; Marchand-Brynaert, J.; Garcia, Y. A simplified approach to N- and N, $N$ '-linked 1,2,4-triazoles by transamination. Synthesis 2008, 1, 149-154.

13. Dîrtu, M.M.; Naik, A.D.; Marchand-Brynaert, J.; Garcia, Y. Room temperature hysteretic spin transition in 1D iron(II) coordination polymers. J. Phys. Conf. Ser. 2010, 217, 012085. 
14. Naik, A.D.; Dîrtu, M.M.; Léonard, A.; Tinant, B.; Marchand-Brynaert, J.; Su, B.L.; Garcia, Y. Engineering three-dimensional chains of porous nanoballs from a 1,2,4-triazole-carboxylate supramolecular synthon. Cryst. Growth Des. 2010, 10, 1798-1807.

15. Naik, A.D.; Beck, J.; Dîrtu, M.M.; Bebrone, C.; Tinant, B.; Robeyns, K.; Marchand-Brynaert, J.; Garcia, Y. Zinc complexes with 1,2,4-triazole functionalized amino acid derivatives: Synthesis, structure and beta-lactamase assay. Inorg. Chim. Acta 2011, 368, 21-28.

16. Dîrtu, M.M.; Neuhausen, C.; Naik, A.D.; Léonard, A.; Robert, F.; Marchand-Brynaert, J.; $\mathrm{Su}$, B.L.; Garcia, Y. Superlative scaffold of 1,2,4-Triazole derivative of glycine steering linear chain to a chiral helicate. Cryst. Growth Des. 2011, 11, 1375-1384.

17. Hagen, K.S. Iron(II) Triflate salts as convenient substitutes for perchlorate salts: Crystal structures of $\left[\mathrm{Fe}\left(\mathrm{H}_{2} \mathrm{O}\right)_{6}\right]\left(\mathrm{CF}_{3} \mathrm{SO}_{3}\right)_{2}$ and $\mathrm{Fe}(\mathrm{MeCN})_{4}\left(\mathrm{CF}_{3} \mathrm{SO}_{3}\right)_{2}$. Inorg. Chem. 2000, 39, 5867-5869.

18. Chwaleba, D.; Ilczyszyn, M.M.; Ilczyszyn, M.; Ciunik, Z. Glycine-methanesulfonic acid (1:1) and glycine-p-toluenesulfonic acid (1:1) crystals: Comparison of structures, hydrogen bonds, and vibrations. J. Mol. Struct. 2007, 831, 119-134.

19. Haasnoot, J.G.; Vos, G.; Groeneveld, W.L. 1,2,4-Triazole complexes, III. Complexes of transition metal(II) nitrates and fluoroborates. Z. Naturforsch. B 1977, 32, 1421-1430.

20. Adriaanse, J.H.; Askes, S.H.C.; van Bree, Y.; van Oudheusden, S.; van den Bos, E.D.; Gunay, E.; Mutikainen, I.; Turpeinen, U.; van Albada, G.A.; Haasnoot, J.G.; et al. Coordination chemistry of 5,6,7-trimethyl-[1,2,4]triazolo[1,5-a]pyrimidine with first-row transition-metal salts: Synthesis, spectroscopy and single-crystal structures, with counter-anion dependence of the structures. Polyhedron 2009, 28, 3143-3149.

21. Sinditskii, V.P.; Fogelzang, A.E.; Dutov, M.D.; Sokol, V.I.; Serushkin, V.V.; Svetlov, B.S.; Poraikoshits, M.A. Structure of complex-compounds of metal chlorides, sulfates, nitrates and perchlorates with carbohydrazine. Zh. Neorg. Khim. 1987, 32, 1944-1949.

22. Nakamoto, K. Infrared and Raman Spectra of Inorganic and Coordination Compounds, Part B, 5th ed.; Wiley-Interscience: New York, NY, USA, 1997.

23. Dîrtu, M.M.; Rotaru, A.; Gillard, D.; Linares, J.; Codjovi, E.; Tinant, B.; Garcia, Y. Prediction of the spin transition temperature in $\mathrm{Fe}^{\mathrm{II}}$ one-dimensional coordination polymers: An anion based database. Inorg. Chem. 2009, 48, 7838-7852.

24. Dîrtu, M.M.; Neuhausen, C.; Naik, A.D.; Rotaru, A.; Spinu, L.; Garcia, Y. Insights into the origin of cooperative effects in the spin transition of $\left[\mathrm{Fe}\left(\mathrm{NH}_{2} \mathrm{trz}\right)_{3}\right]\left(\mathrm{NO}_{3}\right)_{2}$ : The role of supramolecular interactions evidenced in the crystal structure of $\left[\mathrm{Cu}\left(\mathrm{NH}_{2} \mathrm{trz}\right)_{3}\right]\left(\mathrm{NO}_{3}\right)_{2} \cdot \mathrm{H}_{2} \mathrm{O}$. Inorg. Chem. 2010, 49, 5727-5736.

25. Gütlich, P.; Hauser, A.; Spiering, H. Thermal and optical switching of iron(II) complexes. Angew. Chem., Int. Ed. 1994, 33, 2024-2054.

26. Gütlich, P.; Jung, J.; Goodwin, H.A. Molecular Magnetism: From Molecular Assemblies to the Devices; Coronado, E., Delhaès, P., Gatteschi, D., Miller, J.S., Eds.; Springer: Berlin, Germany, 1996; p. 327. 
27. Garcia, Y.; van Koningsbruggen, P.J.; Lapouyade, R.; Fournès, L.; Rabardel, L.; Kahn, O.; Ksenofontov, V.; Levchenko, G.; Gütlich, P. Influences of temperature, pressure, and lattice solvents on the spin transition regime of the polymeric compound $\left[\mathrm{Fe}(\text { hyetrz })_{3}\right] \mathrm{A}_{2} \cdot 3 \mathrm{H}_{2} \mathrm{O}$ (hyetrz $=4$-(2'-hydroxyethyl)-1,2,4-triazole and $\mathrm{A}^{-}=3$-nitrophenylsulfonate). Chem. Mater. 1998, 10, 2426-2433.

28. Garcia, Y.; Niel, V.; Muñoz, M.C.; Real, J.A. Spin crossover in 1D, 2D and 3D polymeric Fe(II) networks; Spin crossover in transition metal compounds. Top. Curr. Chem. 2004, 233, 229-257.

29. Garcia, Y.; van Koningsbruggen, P.J.; Lapouyade, R.; Rabardel, L.; Kahn, O.;Wieczorek, M.; Bronisz, R.; Ciunik, Z.; Rudolf, M.F. Synthesis and spin-crossover characteristics of polynuclear 4-(2'-hydroxyethyl)-1,2,4-triazole Fe(II) molecular materials. C. R. Acad. Sci. 1998, IIc, 523-532.

30. Dîrtu, M.M.; Garcia, Y.; Nica, M.; Rotaru, A.; Linares, J.; Varret, F. Iron(II) spin transition 1,2,4-triazole chain compounds with novel inorganic fluorinated counteranions. Polyhedron 2007, 26, 2259-2263.

31. Garcia, Y.; Ksenofontov, V.; Mentior, S.; Dîrtu, M.M.; Gieck, C.; Bhatthacharjee, A.; Gütlich, P. Rapid cooling experiments and use of an anionic nuclear probe to sense the spin transition of the $1 \mathrm{D}$ coordination polymers $\left[\mathrm{Fe}\left(\mathrm{NH}_{2} \mathrm{trz}\right)_{3}\right] \mathrm{SnF}_{6} \cdot \mathrm{nH}_{2} \mathrm{O}\left(\mathrm{NH}_{2} \operatorname{trz}=4\right.$-amino-1,2,4-triazole $)$. Chem. Eur. J. 2008, 14, 3745-3758.

32. Recoil, Mössbauer Spectral Analysis Software for Windows, Version 1.0; Department of Physics, University of Ottawa: Ottawa, ON, Canada, 1998.

33. Breuer, K.H.; Eysel, W. The calorimetric calibration of differential scanning calorimetry cells. Thermochim. Acta 1982, 57, 317-329.

34. Rotaru, A.; Dîrtu, M.M.; Enachescu, C.; Tanasa, R.; Linares, J.; Stancu, A.; Garcia Y. Calorimetric measurements of diluted spin crossover complexes $\left[\mathrm{Fe}_{\mathrm{x}} \mathrm{M}_{1-\mathrm{x}}(\mathrm{btr})_{2}(\mathrm{NCS})_{2}\right] \cdot \mathrm{H}_{2} \mathrm{O}$ with $\mathrm{M}^{\mathrm{II}}=\mathrm{Zn}$ and Ni. Polyhedron 2009, 28, 2531-2536.

(C) 2011 by the authors; licensee MDPI, Basel, Switzerland. This article is an open access article distributed under the terms and conditions of the Creative Commons Attribution license (http://creativecommons.org/licenses/by/3.0/). 